International Journal of Linguistics, Literature and Translation

ISSN: 2617-0299 (Online); ISSN: 2708-0099 (Print)

DOI: 10.32996/ijltt

Journal Homepage: www.al-kindipublisher.com/index.php/ijltt

IJLLT

\title{
Emerging Netspeak Word Choices in Social Media on Filipino Pop Culture
}

\author{
Camille P. Monderin ${ }^{\mathbf{9}}$ (D) $\triangle$ and Mildred B. Go ${ }^{\mathbf{2}} \mathbf{8}$ (D) \\ ${ }^{1}$ Graduate Student, Centro Escolar University (CEU), Manila, Philippines \\ ${ }^{2}$ Graduate School Professorial Lecturer, Centro Escolar University (CEU), Manila, Philippines
}

$\triangle$ Corresponding Author: Camille P. Monderin, E-mail: monderin1715363@ceu.edu.ph / cpmonderin@gmail.com

\section{ARTICLE INFORMATION ABSTRACT}

Received: May 01, 2021

Accepted: June 18, 2021

Volume: 4

Issue: 6

DOI: 10.32996/ijllt.2021.4.6.7

\section{KEYWORDS}

Netspeak, word choice, lexical patterns, pop culture, social media accounts, Internet linguistics
The emergence of the Internet gave birth to a new form of language that is unique to the users of the network. Netspeak is the language of the Internet and has adapted the features of both speaking and writing; however, Netspeak has its own unique characteristics as well. This study aimed to find the emerging lexical patterns of Netspeak as used by Filipinos, the extent of use of Netspeak in three most popular social media platforms (Facebook, Instagram and Twitter) as well as various domains of pop culture (entertainment, politics, fashion and sports) and its implications to the language studies in the Philippines. Both qualitative and quantitative methods were used in this study. The corpora of the study were gathered from two months' worth of social media activities focusing on the comments in the Facebook, Instagram and Twitter of selected public figures. The findings showed that the emerging lexical patterns of Netspeak were abbreviations and homophones and that social media platforms and pop culture domains affect the use of Netspeak features. The platform and domain that got the greatest extent of usage of Netspeak lexical features were Twitter and Politics, respectively. The results of this study will help understand the language used on the Internet and raise awareness that this kind of language exists.

\section{Introduction}

Language is constantly evolving and new stylistic variations of language as well as new forms of communication. The advancement of technology has been a factor in the development and evolution of language, most prominently with the emergence of the Internet where its users have developed their own language, their own form of communication, one that is unique to the users of the network. People are now able to communicate easily and are also able to exchange ideas and thoughts faster. The Internet provides its users with various ways to interact such as e-mail, chat messages, blogs, as well as the use of the more popular social media sites: Facebook, Twitter, Instagram, Tumblr, YouTube, Snapchat, etc. As people communicate more frequently through the Internet, the language has adapted to the one that its users use.

There were a few coined terms that could define and describe this language: "Netlish", "Weblish", "Internet language", and "CMC" or "Computer-Mediated Communication". These terms, however, do not properly describe the language of the Internet and are not enough to define it. Netlish is simply a combination of Net and English, which merges the terms used as the Internet is becoming more multilingual. This is the same case with Weblish, which is also a combination of Web and English. Although majority of the Internet users use English, there are also a few languages that are not far behind in usage. As of early 2020, English was the most popular language online, being used by 25.9 percent of worldwide Internet users, followed by Chinese with 19.4 percent of users. Following on the list is Spanish with 7.9 percent, then Arabic with 5.2 percent, Indonesian/Malaysian with 4.3 percent, Portuguese with 3.7 percent, French with 3.3 percent, Japanese with 2.6 percent, Russian with 2.5 percent, German with 2 percent, and lastly, the rest of the languages not mentioned with 23.1 percent (Clement, 2020). The top ten languages accounted for 76.9 percent of Internet users globally. This shows that as the Internet becomes more popular and more widespread, users from different parts of the world take part in using the Internet in which languages other than English are

\section{K C AL-KINDI CENTER \\ $\mathbf{R}$ D FOR RESEARCH AND DEVELOPMENT}

Your gateway to world-class research

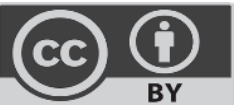

Published by Al-Kindi Center for Research and Development, London, United Kingdom. Copyright (c) the author(s). This open access article is distributed under a Creative Commons Attribution (CC-BY) 4.0 license 
used, so the terms Netlish and Weblish, which specified English in its term cannot be used to describe the language which is becoming increasingly multilingual. The other mentioned term to describe the language of the Internet, CMC or ComputerMediated Communication, emphasizes the medium for using Internet, and not the language itself. In order to properly describe the Internet language, Crystal coined the term "Netspeak" as an alternative to all the previously mentioned locutions. He stated that Netspeak is "succinct and functional enough" and clarified that speak includes both talking and writing and "that any speak suffix also has a receptive element, including listening and reading" (Crystal, 2001). The term presented by Crystal not only covers the Internet, which is the medium, but also "speak" which is the language itself. The term Netspeak is generic enough to include all languages that are used in Internet but is also specific enough to show that the term is meant for describing the Internet language. The term and its definition provided by Crystal fits the researcher's idea of the language of the Internet. The present study subscribed to Crystal's term and description and used "Netspeak" to describe Internet language.

Netspeak as a language is neither spoken nor written: it has the features of both speaking and writing in order to suit the medium, which is the Internet, and also has different features that neither speaking nor writing could ever deliver (Crystal, 2001). In Crystal's book, Language and the Internet (2005), he described the salient features of the language of the Internet and how the Internet affects the use of language. The features included lexicon, neologisms, abbreviations, acronyms, capitalization, spelling, punctuation, and the use of smileys or emoticons. Later investigations, such as that of Yeo and Ting (2017), corroborated these features of Netspeak found by Crystal (2005). However, in their investigation, Yeo and Ting (2017) found features that are not identified in Crystal's book, and these features include the addition or replacement of letters, vowel dropping, homophone, negation, codeswitching, using of "2" for repeating words, and spacing. As the Internet is full of people from different backgrounds, countries, cultures, and languages, some features of Netspeak may be present in some languages and some may not. These features that are present in some languages may be specific to those countries or the speakers of the languages, which may or may not be influenced by their own culture. As shown in the additional features found by Yeo and Ting in their study, which focused on Malaysian university students, there is a possibility that a country's language may have its own unique features of Netspeak. The researcher believes this phenomenon to be present in the context of the Philippine Internet language as well.

On the other hand, culture is defined as "socially constructed or learned behavior" (Ohiagu and Okorie, 2014). Culture is the behavior characteristic of a particular social group. Culture shapes language and language reflects culture. Dominick (2013), cited in Ohiagu and Okorie (2014), described culture as a "complex concept that refers to the common values, beliefs, social practices, rules and assumptions that bind a group of people together". The use of Netspeak on the Internet gives identity to the users as part of the same group as they can understand each other and recognise the language they are using. As part of the same community, these people can communicate using Netspeak when others may have difficulty doing so. Ohiagu and Okorie further stated that "culture is a learned and repetitive behavior, which is imbibed through regular exposure to others' lifestyles and shared with others who also adopt the same values. This notion of culture can be narrowed down to popular culture or pop culture, as all socially acquired traditions and lifestyles learned and made popular through the media".

This study is interested in investigating the lexical patterns of Netspeak in Filipino social media and pop culture. Precisely, the following research questions guided the analysis:

(1) What was the extent of usage of each of the Netspeak features across the three most popular social media platforms (Facebook, Instagram and Twitter)?

(2) What was the extent of usage of each of the Netspeak features across the domains of pop culture (Entertainment, Fashion, Politics and Sports)?

(3) What were the emerging lexical patterns of Netspeak in Filipino social media and pop culture?

(4) What are the implications of the findings of the study to language studies in the Philippines?

\section{Literature Review}

Netspeak Word Choices is a feature of Netspeak that focuses on the lexical aspect of the language instead of the mechanics, styling, or other linguistic feature. This study focused on the following word choices only: 1) abbreviations, 2) acronyms, 3) homophone 4) onomatopoeia, and 5) neologisms.

Wang and Wang (2017) described an abbreviation as a new word created by deleting a part of the original word and using what is left of the word. Crystal, cited in Nasir and Al-Ghizzy (2019), argued that "abbreviation or shortening means that a word is shortened by omitting one of its meaningful elements usually at the end such as 'exam' but sometimes at the beginning such as 'phone'". Although a part of the word has been omitted, the word is still intelligible to the receivers. Abbreviations shorten the word but the meaning does not change, nor is it altered. In abbreviations, the deleted part is not limited to the front or back of the word; deletion may occur in the middle of the word like the word "thanks" which can be abbreviated to "thx" or "tnx".

Page | 50 
An acronym is forming new words by combining the first letters of each word in a phrase or title. In Netspeak, however, acronyms are not limited to a few words or short phrases but can also extend to sentences (Crystal, 2001). This is reflected in the study of Nasir and Al-Ghizzy (2019) who stated that morphologically, acronyms are formed from the first letters of other words or other phrases; however, in Netspeak, sentence-length acronyms occur such as "IKR" which stands for "I know, right?".

Online communication uses other means to show emotions to address the lack of facial expressions, actions, and gestures that can be seen in face-to-face communication, and using onomatopoeia is one way to bridge the gap. The use of onomatopoeias in social media make the language richer and more impressive. As the language on the Internet leans toward written communication, the use of onomatopoeia helps its users make the communication alive by imitating sounds, using words to add expressions to the conversation.

In Netspeak, a homophone is described as replacing a word with a similar-sounding word or a letter, often in a shortened form (Yeo and Ting, 2017). They also stated that "the use of homophone by the users is influenced by the way they speak when they type, thus this is considered as the spoken feature of social media communication". David Crystal has mentioned that netspeak is neither written nor spoken communication; however, it has adapted features from both and added more. This feature of Netspeak shows how speaking has influenced the way of writing on the Internet and how it is manifested.

The previously mentioned features_abbreviation, acronym, onomatopoeia, and homophone-have the same characteristic: the spellings change from their original words, but the meanings are retained. However, new lexicons on the Internet such as coined terms from the digital nature of the medium, are mainly created by new expressions and words (Villares, 2017). The final feature of Netspeak deals with word meanings, meaning deviation, and the creation of new words that are influenced by the Internet.

Neologism refers to a freshly coined term or expression. Netspeak lexicon is full of fresh and creative words that are apparent from the number of abundant coined terms on the Internet. However, a neologism is limited to creating a new word and giving a new meaning to an old word (Liu and Liu, 2014). Liu and Liu also stated that "the most noticeable characteristic of Netspeak is the neologisms, and the essence of neologisms lies in the word-formation". The citizens of the Internet come up with many words that can trend by being popular to the users of social networking sites, and by permeating to the language used in these platforms, these words slowly integrate into the vocabulary that is widely used on these platforms the Internet. The creativity and ingenuity of these people go beyond giving new definitions of existing words; the people of the Internet sometimes invent a new word or phrase to better fit and express what they want to say. This study focused only on three word-formation processes including blending, coinage, and slang words.

Blending is the process of forming words by taking parts of two separate words and combining them to form a whole new word. The process of blending involves combining parts of at least two words where there is some form of syllabic overlap between them. Blending in netspeak not only combines parts of the words but also their meanings. The emergence of the Internet has ushered in new varieties of English with changes seen in vocabulary, grammar, spelling and pronunciation. A series of new words have been created and used with the help of the Internet. The words created on the Internet are sometimes influenced by the platform where they originated. The word "hashtag" is popularized on Twitter and is originally used to organize tweets with the same topic. However, the hashtag is now used to gain attention from other people by including many hashtags in their posts, which in turn heightens their visibility in the social media platform gaining traffic in their profile. The word "unlike" came from Facebook, where after liking a post, the word "Like" will change into "Unlike" if the person wants to change his/ her response to the post. The word "unfriend" also originated from Facebook which means to remove someone from the friends' list on a social networking website. These words have then been used by the users of Facebook and become an accepted word by the community. The advancement of technology has also influenced the creation of new words on the Internet, like download and upload. These factors have contributed to enriching the language used on the Internet.

The deviation of the meaning of a word from its original one is Netspeak's novelty. Slang words in this study refer to words that have deviated from their original meanings when used in social media. Slang may also refer to the slang that is used in the Philippines that has been popularized and used on the Internet. Internet slang words used on the Internet are influenced by the different backgrounds, culture, countries, age, race, and language of their users. As the meanings vary from person to person, some slang words might have different meanings depending on the person, context, or setting. Some slang words may also be exclusive to a specific country or language only.

Pop culture is an inevitable part of netspeak as pop culture influences the changes in Netspeak and vice versa as social media shapes pop culture. In order to find the role of social media in the construction and transmission of popular culture, Ohiagu and Okarie (2014) conducted a study by analyzing forty Facebook pages, 20 blogs, and 20 Twitter accounts. They stated that "Language is an important component of popular culture that formed the base for this research". Culture, nowadays, is not 
limited to verbally transmitted culture nor printed form of culture. Culture has also been extended to other forms of media like the Internet. "Again, pop culture spans far beyond language whether spoken, written, or digitized" (Ohiagu and Okarie, 2014). Their research concluded that "social media interactions contribute significantly to the production and circulation of popular culture expressions in the virtual world". They stated that social media make this possible by creating new words and making these new words popular that people of the Internet can understand even across borders, leading to global culture. As these words become popular, the users then become exposed to the emerging trend and pick up on the meaning as they continue seeing and using them.

The Philippines is no exception to the exposure and usage of netspeak. The use of Netspeak in the Philippines has been the subject of Gustilo and Dino's (2017) study where they researched if Netspeak is a language used only by the younger generation,or if it is the language that is used regardless of age group. They clustered their respondents according to their ages which they limited to people whose ages fell in three categories: 15-25, 26-35, and 36-50. After analyzing the social media accounts of their respondents, they found that Netspeak is not exclusive to the younger generation and that people in different age groups use Netspeak as well. People in the age brackets 26-35 and 36-50 were found not to remain conservative when using social media and not using the standard form of English, which shows that Netspeak is not only used by young people also by people of varying age groups. The features of Netspeak that were found in the study included "no punctuation" which got the highest frequency among all features, followed by "acronymy", "retention", "capped expressions", "punctuations", "intrasentential code switching", "synecdoche", "transcription of cry", "hashtag", and "taboo". The features related to word choices are acronymy, synecdoche, transcriptions of cry or onomatopoeia, and taboo. These features found in the study helped in giving the researcher an idea of what the data might look like for data gathering.

Netspeak in the Philippines is a topic that has been rarely researched, especially in the context of Filipino social media. Other studies referenced in this study has focused on their local language in addition to English as well, and this is what the researcher has also done in order to shed light on Netspeak as well as lexical features that might have unique qualities.

\section{Methodology}

This study aimed at finding the emerging lexical patterns of Netspeak in social media accounts of Filipinos, as well as its extent of use in the three most popular social media platforms and four pop culture domains. To accomplish this goal, the descriptive method was used. Descriptive research aims at describing a phenomenon and its characteristics. In descriptive research, "the data may be collected qualitatively, but it is often analyzed quantitatively, using frequencies, percentages, averages, or other statistical analyses to determine relationships" (Nassaji, 2015). This kind of research focuses more on the what rather than the how or why.

The corpora of the study were gathered from the comment threads in Facebook, Instagram, and Twitter of twenty (20) popular public figures, 5 for each domain of pop culture, from January 2020 to February 2020. The public figures under were chosen generally based on the following criteria:

a. They have public or official accounts/pages in all 3 platforms.

b. They need to have at least 1 verified account among the 3 platforms; if there is no verified account, they must be recognized or tagged by another verified account.

c. Official accounts in different platforms must be linked or tagged in other social media accounts.

d. They have made names for themselves in their specific field of career.

The data gathering technique used in this study was data mining. Data mining is defined as a process used to extract usable data from a larger set of any raw data. The usable data here refer to the Netspeak that the researcher is collecting, while the set of raw data consisted of the comments from the social media accounts of the public figures. The corpora were collected by combing through countless comment threads and extracting only those that contain Netspeak. Data mining helps in analyzing large databases in order to generate new information. It is a process of finding the patterns within large data sets.

As the corpus of the study was taken from the Internet, the privacy of the social media users was highly observed. In the analysis and discussion, no names, usernames, and profile pictures were shown in the body of research to ensure that private information is not released. All names, user names, and profile pictures were covered.

\section{Results and Discussion}

\subsection{Netspeak in Facebook, Instagram and Twitter}

The results and discussion is presented following the order of the research questions. Data revealed that Twitter had the highest usage among its users among the three social media platforms, followed by Instagram and lastly, Facebook. Further revealed is that Abbreviation is the netspeak feature with the highest usage among the netspeak features included in the study while 
blending is last. The descriptive analysis of the extent of usage of each of netspeak features in Facebook, Instagram and Twitter is presented in Table 1.

Table 1. Extent of Usage of Netspeak in Social Media Platforms

\begin{tabular}{ccccccccc}
\hline & Abbreviation & Homophone & Acronym & Onomatopoeia & Slang & Coinage & Blending & Total \\
\cline { 2 - 8 } Twitter & 356 & 280 & 410 & 360 & 191 & 97 & 16 & $\mathbf{1 7 1 0}$ \\
Instagram & 465 & 285 & 270 & 299 & 223 & 17 & 27 & $\mathbf{1 5 8 6}$ \\
Facebook & 437 & 382 & 245 & 202 & 194 & 41 & 29 & $\mathbf{1 5 3 0}$ \\
\hline Total & 1258 & 947 & 925 & 861 & 608 & 155 & 72 & 4826 \\
\hline
\end{tabular}

Among the three social media platforms, Twitter has the highest frequency count for Netspeak usage and within this social media platform, acronym is the most used feature. The most popular acronyms used in this platform was "ily" followed by "omg" and then "Iol". In a study mentioned in the related literature, "lol" usually occupied the first rank in usage among acronyms, like that of Nasir and Al-Ghizzy (2019) where "lol" had the highest frequency count among all the acronyms in their studies of netspeak in social media. However, in this study although in a high place, it is only the third highest with a different acronym, "ily", being the most popular in usage. The reason can be attributed to the fact that the comments were meant for public figures. Therefore, adoration and sentiment were behind this high usage of "ily" instead of "Iol" that is mostly used to react to their posts. Meanwhile, onomatopoeia is also found in high frequency on the Twitter platform. Onomatopoeic words found in the study can be categorized into three: 1) laughter, 2) cry and 3) Internet onomatopoeia. These onomatopoeic words help in making the language and communication in the Internet more expressive and creative. There are various ways to show laughter and its degrees: 1) haha, for standard laughter, 2) hihi, a giggle, 3) hehe shy/smug laugh and 4) hoho, the "Santa" laugh. However, there is only one way to express it for crying - huhu, the standard way of showing sadness or crying in text. There is also an onomatopoeia that is exclusive to the Internet, sksksk. These different ways of typing emotive language help in expressing the needed emotion that the users want to convey in their comments without relying on the use of emojis, emoticons and such.

Abbreviation was used in Instagram more than in Facebook and Twitter, with a total frequency count of 465 in this platform alone. Two of the most popular abbreviations used in this platform include "pic" and "fave" which are shortened forms of "picture" and "favorite". As Instagram is a social networking site that is photo and video-centric, the word "pic" had been used in the comments to refer to the post made by public figures. On the other hand, slang had the highest frequency count in Instagram than Facebook and Twitter. The most popular slang used in this platform is a Filipino slang sana all which literally translates to "hope everyone experiences that" is used to show that the person hopes for the same thing as the post and it is not limited to material possessions but extends to experiences, achievements, success, luck etc. As slang may differ in meanings based on contexts and the community where the slang is used, it is imperative to know who the receivers are in order to avoid misunderstanding and miscommunication. The use of slang needs to be in an appropriate situation, and it can not be used carelessly especially when some slangs can be offending to others.

In Facebook, a homophone is a highly used netspeak feature. The use of homophone to replace similar-sounding sounds was very common on this platform. As homophones are used to replace similar-sounding words with another letter, there were instances where a variety of homophones were used in a single comment, as seen in the comment: luv $u$ meme $u$ always make my day happy, where both u's were used to replace the word you. Yeo and Ting (2017) stated that homophones are influenced by the way they speak when they type, therefore mimicking how these words were pronounced and then spelling them that way. This, of course, differs depending on the language used, as seen in comment 1, which used the English language, the word you is simply the single letter $\mathrm{u}$. Meanwhile, in the comment: Gusto ko xa ma meet meme... Regalo mo sakin (I would like to meet them mommy... As your gift to me), which used Filipino language, the word siya was replaced by $x a$ where the sound of letter $x$ in the Filipino language is similar to sh- which is then used to replace the first sound in siya /sha/. The word siya in Filipino is a genderneutral third-person pronoun for he/she in English.

The language used in the social media platforms has evolved creatively in order to suit the particular needs of its users, including but not limited to typing space, effort, and creative expressions. The uniqueness of each platform has given way to the creation and usage of language that is fit for the situation. The platforms have also influenced the type of Netspeak used in each of the platforms. As medium for communication, these platforms introduce new words on a regular basis which get exposed to the users who adopt the changes. 


\subsection{Netspeak in Entertainment, Fashion, Sports and Politics}

Data revealed that among the four pop culture domains included in the study, Politics had the highest usage among its users, followed by Entertainment, then Sports, and Fashion. Further revealed is that Abbreviation is the netspeak feature with the highest usage among the netspeak features included in the study while blending is last. This result is the same as that of the social media platforms. The descriptive analysis of the extent of usage of each of netspeak features in Entertainment, Fashion, Sports and Politics is presented in Table 2.

Table 2. Extent of Usage of Netspeak in Pop Culture Domains

\begin{tabular}{ccccccccc}
\hline & Abbreviation & Homophone & Acronym & Onomatopoeia & Slang & Coinage & Blending & Total \\
\cline { 2 - 9 } Politics & 300 & 254 & 335 & 214 & 128 & 98 & 5 & $\mathbf{1 3 3 4}$ \\
Entertainment & 177 & 273 & 244 & 337 & 239 & 20 & 35 & $\mathbf{1 3 2 5}$ \\
Sports & 506 & 212 & 202 & 115 & 114 & 20 & 5 & $\mathbf{1 1 7 4}$ \\
Fashion & 275 & 208 & 144 & 195 & 127 & 17 & 27 & $\mathbf{9 9 3}$ \\
\hline Total & 1258 & 947 & 925 & 861 & 608 & 155 & 72 & 4826 \\
\hline
\end{tabular}

Among all the pop culture domains, Politics had the highest frequency count. The acronym is the most common netspeak used in Politics. The nature of acronyms used in this domain is very well related to politics. The researcher found that the names of organizations, cities, and government institutions were mostly in acronym forms in the corpus. The researcher observed that the acronym mostly used in this domain was "VP" which refers to Vice President, which is one of the public figures chosen to be included in the study. The convenience of using acronyms instead of typing the whole word is what makes this Netspeak popular with the users. This Netspeak is not limited to shortening institution names and other formal words; it can also be used in conversational phrases, making it a very helpful tool, especially in platforms with character limits. Coinage had a low ranking within Politics itself but the frequency count of 98 is already the highest among the four pop culture domains. Samples of coinage found in the corpus of Politics were few, to begin with; however, in this domain, a certain coined word was repeatedly used in the comments. The majority of this netspeak frequency belongs to fake news, a coined word to describe information presented as news to mislead and misinform. The spread of fake news can be attributed to political agenda wherein social networking sites and online news outlet played a big part in influencing public opinion and national discourse (Besmano et al., 2017). This spread led to the usage of the term in social media where its users identify information without a credible source as such; however, the term can also be misused by the personal political beliefs of people who label news 'against' their beliefs as fake news even if it comes from a credible source. The active exchange between social media users in the Philippines, particularly when it comes to politics, sometimes leads to arguments with different claims from each side, further proliferating fake news as each side has his/her own 'credible' sources. The engagement of its users leads to long conversations, usually on two opposing sides, both citing their own sources to further their claims. The spread of news in the digital platforms had steered different forms of media manipulation (Pangrazio, 2018), which led to creating the term, fake news, that defines this phenomenon.

Among the pop culture domains, entertainment had the second-highest overall usage of netspeak features. Netspeak words found in the comments of the entertainment domain totaled 1325 where the feature with the highest frequency count was onomatopoeia with 337 or 25.43 percent of the total. This frequency count is the highest among the four pop culture domains. This result meets the expectation of the researcher because as she was observing the social media accounts of the public figures in the entertainment domain, a lot of comments had onomatopoeias in them, most especially in Vice Ganda's and Mimiyuuh's accounts. As both are known for their comedic acts and humor, the comments were filled with the transcription of laughter. As texts lack the visual representation to convey specific emotions, varied spellings are used to distinguish small differences. There are degrees of laughter used in the text, including giggle, shy/smug or the Santa laugh. There is a lot of emotional nuance that is hard to convey through writing. In the speech, people use intonation to convey differences in expressive meanings like happiness, surprise, wariness, ire, etc. These subtle differences in emotions are hard to translate to writing, especially in the standard language. Netspeak helps bridge that gap with the use of creative spelling, word choice, and narrative. On the other hand, Internet slang used in the entertainment domain had a frequency count of 239 or 18.04 percent of the total netspeak found in the Entertainment domain. "Sana all" alone was used 76 times in the comments in this domain. The slang "skkrrttt" was also found in high frequencies, which is a slang popularized by Mimiyuuhh and has been imitated by the people in their comments. As stated by Ohiagu and Okorie (2014), popular media shape social media contents. As public figures, the language used by these people are often imitated by the fans and become part of their lexicon by exposure and usage.

Among the four domains of pop culture, Sports was leading when it comes to abbreviation usage. The most popular abbreviation used was "congrats" with 294 occurrences, which was still the highest of all pop culture domains. The Philippines was the host of the Southeast Asian Games where a lot of our athletes won gold for the country. Big competitive events had influenced the usage of "congrats" in the comment sections of the public figures social media accounts, especially if they themselves secured a place in the competition. The most common abbreviations used in the comments were the words congrats 
followed by bday and tnx. As the comments that were analyzed were from the posts of a public social figure, congratulatory messages were abundant when there was a birthday celebration or when the public figure won a national competition. This can be interpreted as occasions having an influence on the type of Netspeak used by the people. Meanwhile, acronym in this pop culture domain had a frequency count of 202 or 17.21 percent of the total Netspeak found. There were few instances where the pop culture domain influenced the acronym used in the comments. As this is the Sports domain, acronyms related to the sports team or sports icon were often mentioned including NSD which stands for Never Say Die, a phrase associated with the local basketball team, Brgy. Ginebra. The term came to life because of the team's tenacity despite huge score differences and gaining a close victory in their games. It is a term widely used by the fans when the odds are against the team but they still believe that they will overcome these and win. The acronym NSD is a local acronym intended for the local basketball team and, therefore, will not have the same meaning outside the Philippines and Philippine contexts.

The Fashion domain had the lowest overall usage of netspeak features. Netspeak words found in the comments totalled 993 where the feature with the highest frequency count was abbreviation. Netspeak was used the least in this domain. It was the only domain whose netspeak total was below 1000. The abbreviations found in this domain include but are not limited to congrats, pls, fave and adorbs. The abbreviation adorbs is short for adorable. The word was clipped on the last part and was added an -s mainly for ease of pronunciation instead of just stopping at the last letter and ending it abruptly when pronouncing. In social media, where these public figures can post their fashion, a lot of comments were made in reference to their styling. The word adorbs was used to describe the look of that person. On the other hand, the slang feature, although low in rank in this domain, was domain-specific as some slangs were found only in this domain. Slangs like slaying, killing it, bomb and on fleek were used to describe someone's appearance or style which is why it had a higher occurrence rate in the Fashion domain more than in any other domain. Most of the slangs pertain to the fashion itself, making it a unique aspect of the domain.

Netspeak features found in the pop culture domains were influenced by the domains themselves. The occurrence of domainspecific words in the political domain such as fake news and troll shows that there are netspeak that were created from the phenomena that happened in that particular domain. As expected of the Entertainment domain, onomatopoeia with transcriptions of laughter having high frequencies, as well as the mimicking of certain catchphrase, shows the influence of the public figures on the language used in the comments. As for the sports and fashion domains, netspeak that were unique included local terms as well as events limited to the domain themselves. Competitions and celebratory events also influenced what netspeak was used in these domains as people are inclined to comment congratulatory messages if there is an occasion like winning gold for the country, having a birthday party or anniversary, etc.

\subsection{Emerging Lexical Patterns of Netspeak}

Among all of the Netspeak, abbreviations had the highest frequency count, with a total of 1258 or 26.07 percent of the total netspeak found in the corpus. This was followed by homophone with a 947 count or 19.62 percent, then acronym with 925 or 19.17 percent, onomatopoeia with 861 or 17.84 percent, slang with 608 or 12.60 percent and coinage with 155 or 3.21 percent. The least used netspeak feature across the social media platforms and pop culture domains was blending with a frequency count of only 72 or 1.49 percent. The total count of Netspeak found in the corpus was 4826 .

Table 3. Emerging Lexical Patterns of Netspeak

\begin{tabular}{lcccccccc}
\hline \multirow{2}{*}{ Frequency } & Abbreviation & Homophone & Acronym & Onomatopoeia & Slang & Coinage & Blending & Total \\
\cline { 2 - 8 } Percentage & 1258 & 947 & 925 & 861 & 608 & 155 & 72 & 4826 \\
& $26.07 \%$ & $19.62 \%$ & $19.17 \%$ & $17.84 \%$ & $12.60 \%$ & $3.21 \%$ & $1.49 \%$ & $100 \%$
\end{tabular}

The emerging lexical patterns of Netspeak were further analyzed to investigate and describe their characteristics.

\section{A. Abbreviation}

A total of 105 different abbreviations were found in this study. The formation of abbreviations can be analyzed from the perspective of their structure. 
Figure 1. Partial List of Abbreviations Found in the Corpus

\begin{tabular}{|r|l|l|c|l|}
\hline No. & Item & Expansion & Lexical Pattern (Netspeak) & Type \\
\hline 1 & abt & about & Abbreviation & Middle Clipping \\
\hline 2 & ad & advertisement & Abbreviation & Back Clipping \\
\hline 3 & admin & administrator & Abbreviation & Back Clipping \\
\hline 4 & adorbs & adorable & Abbreviation & Clipping with Spelling Change \\
\hline 5 & aircon & air conditioner & Abbreviation & Back Clipping \\
\hline 6 & anniv & anniversary & Abbreviation & Back Clipping \\
\hline 7 & app & application & Abbreviation & Back Clipping \\
\hline 8 & bb & baby & Abbreviation & Middle Clipping \\
\hline 9 & bcz & because & Abbreviation & Clipping with Spelling Change \\
\hline 10 & bday & birthday & Abbreviation & Middle Clipping \\
\hline 11 & bec & because & Abbreviation & Back Clipping \\
\hline 12 & becoz & because & Abbreviation & Clipping with Spelling Change \\
\hline 13 & bes & best friend & Abbreviation & Back Clipping \\
\hline 14 & bio & biography & Abbreviation & Back Clipping \\
\hline 15 & bldg & building & Abbreviation & Middle Clipping \\
\hline 16 & blvd & boulevard & Abbreviation & Middle Clipping \\
\hline 17 & Brgy. & Barangay & Abbreviation & Back Clipping \\
\hline 18 & bro & brother & Abbreviation & Back Clipping \\
\hline 19 & cam & camera & Abbreviation & Back Clipping \\
\hline 20 & celeb & celebrity & & \\
\hline
\end{tabular}

According to the structure of the abbreviations found in the corpus collected, they can be organized into four types:

a. Front clipping is the deletion of the part of the word that occurs at the initial part of the word.

b. Middle clipping is the deletion in the middle of the word, where several letters are dropped in between the first and last part of the word. Sometimes, letters in the last part of the word are also dropped.

c. Back clipping is the deletion at the last part of the word, sometimes completely dropping the last part.

d. Clipping with spelling change is the deletion in the first or last part of the word with added letters at the end to complete the abbreviation, which is usually not present in the deleted part of the word. These added letters at the end make it so that the word does not end abruptly or awkwardly.

\section{B. Homophone}

There were 43 homophones found in the study. The homophones found in this study were limited to English and Filipino homophones.

Figure 2. Partial List of Homophones Found in the Study

\begin{tabular}{|c|c|c|c|c|}
\hline No. & Item & Replaced Word/Sound & Lexical Pattern (Netspeak) & Type \\
\hline 1 & 2 & dito* & Homophone & Filipino Homophone: Number \\
\hline 2 & 2 & to & Homophone & English Homophone: Number \\
\hline 3 & 2 & tooday & Homophone & English Homophone: Number \\
\hline 4 & 4 & for & Homophone & English Homophone: Number \\
\hline 5 & b & $\mathrm{ba}^{*}$ & Homophone & $\begin{array}{l}\text { Filipino Homophone: Single letter to } \\
\text { whole word }\end{array}$ \\
\hline 6 & b & be & Homophone & $\begin{array}{l}\text { English Homophone: Single letter to } \\
\text { whole word }\end{array}$ \\
\hline 7 & bz & busy & Homophone & $\begin{array}{l}\text { English Homophone: Multiple letters } \\
\text { to whole word }\end{array}$ \\
\hline 8 & c & see & Homophone & $\begin{array}{l}\text { English Homophone: Single letter to } \\
\text { whole word }\end{array}$ \\
\hline 9 & c & si & Homophone & $\begin{array}{l}\text { Filipino Homophone: Single letter to } \\
\text { whole word }\end{array}$ \\
\hline 10 & $\mathrm{c}$ & $\underline{\text { sila } / \text { sige } / \text { siya }}{ }^{*}$ & Homophone & Filipino Homophone: Syllabic \\
\hline 11 & d & di (hindi)/dito* & Homophone & Filipino Homophone: Syllabic \\
\hline 12 & $\mathrm{~d}$ & the & Homophone & $\begin{array}{l}\text { English Homophone: Single letter to } \\
\text { whole word }\end{array}$ \\
\hline 13 & $\mathrm{~d}$ & that $/$ them/this & Homophone & $\begin{array}{l}\text { English Homophone: Single letter to } \\
\text { similar sound }\end{array}$ \\
\hline 14 & $\mathrm{~d}$ & 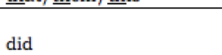 & Homophone & $\begin{array}{l}\text { English Homophone: Single letter to } \\
\text { whole word }\end{array}$ \\
\hline 15 & $\mathrm{db}$ & diba (hindi ba)* & Homophone & $\begin{array}{l}\text { Filipino Homophone: Multiple letters } \\
\text { to whole word }\end{array}$ \\
\hline
\end{tabular}

According to the homophones found in the corpus collected, they can be organized into two types, which can further be analyzed and categorized as follows:

a. English Homophones are letters in the English alphabet that are used as a replacement for a similarsounding word or similar sound in the word. English homophones found in the study can be categorized into four:

i. Single letter to whole word replacement is a kind of homophone where a single English alphabet letter is used to replace the whole word which sounds similar to the letter.

ii. Single letter to similar sound replacement is a kind of homophone where a single English alphabet letter is used in replacing only the similar-sounding part of the word. 
iii. Multiple letters to whole word replacement is a homophone where a combination of a few letters act as a replacement for the similar-sounding word.

iv. Number homophones are homophones that use numbers in replacement for a similar-sounding word.

b. Filipino Homophones are letters in both the English and Filipino language used in replacing similarsounding Filipino words. The same categories of homophones also apply to the Filipino language; however, there was an additional category present in Filipino homophones that were found in this study:

i. Syllabic replacement is a homophone where a single letter replaces only a syllable of a similarsounding word. This differs from the single letter to a similar sound replacement category as this kind of homophone is pronounced as a syllable in a similar-sounding word, whereas a single letter to a similar sound replacement category is pronounced together with the remaining letters of the word.

\section{Acronym}

A total of 153 acronyms was found in this study. There were acronyms that were based in the Philippines, mostly of the government institutions, local cities, local TV shows and personalities, etc.

Figure 3. Partial List of Acronyms Found in the Study

\begin{tabular}{|c|c|c|c|c|}
\hline No. & Item & Expansion & Lexical Pattern (Netspeak) & Type \\
\hline 1 & afi & awaiting further instructions & Acronym & Phrasal Acronym: Initialism \\
\hline 2 & asap & as soon as possible & Acronym & $\begin{array}{l}\text { Phrasal Acronym: Pronounced } \\
\text { as a new word }\end{array}$ \\
\hline 3 & ASAP (show) & All-Star Sunday Afternoon Party* & Acronym & $\begin{array}{l}\text { Standard Acronym: } \\
\text { Pronounced as a new word }\end{array}$ \\
\hline 4 & ASF & Age, Sex, From & Acronym & Standard Acronym: Initialism \\
\hline 5 & AWOL & absent without official leave & Acronym & Standard Acronym: Initialism \\
\hline 6 & bf & boyfriend & Acronym & Single-word Acronym \\
\hline 7 & bff & best friend forever & Acronym & Phrasal Acronym: Initialism \\
\hline 8 & BFRV & Banco Filipino Resort Village* & Acronym & Standard Acronym: Initialism \\
\hline 9 & BGC & Bonifacio Global City* & Acronym & Standard Acronym: Initialism \\
\hline 10 & BGSM & Barangay Ginebra San Miguel* & Acronym & Standard Acronym: Initialism \\
\hline 11 & BIG & Believe in God & Acronym & \begin{tabular}{|l|} 
Sentence Acronym: \\
Pronounced as a new word
\end{tabular} \\
\hline 12 & bs & bullshit & Acronym & Single-word Acronym \\
\hline 13 & bts & behind the scene & Acronym & Phrasal Acronym: Initialism \\
\hline 14 & btw & by the way & Acronym & Phrasal Acronym: Initialism \\
\hline 15 & BYOB & Bring Your Own Bag & Acronym & Standard Acronym: Initialism \\
\hline 16 & $\mathrm{CCF}$ & Christ's Commission Fellowship* & Acronym & Standard Acronym: Initialism \\
\hline 17 & CG & \begin{tabular}{|l} 
Catriona Gray* \\
\end{tabular} & Acronym & Standard Acronym: Initialism \\
\hline 18 & CLOY & Crash Landing On You & Acronym & $\begin{array}{l}\text { Standard Acronym: } \\
\text { Pronounced as a new word }\end{array}$ \\
\hline 19 & $\mathrm{COA}$ & Commission on Audit* & Acronym & $\begin{array}{l}\text { Standard Acronym: } \\
\text { Pronounced as a new word }\end{array}$ \\
\hline 20 & $\mathrm{cp}$ & cellphone & Acronym & Single-word Acronym \\
\hline
\end{tabular}

*Filipino Acronyms

The formation of acronyms used by the participants in their comments were analyzed and organized into three types, which were further analyzed and categorized as follows:

a. Standard Acronyms are words that are related to names, events, places, organizations, institutions, or any other formal terms used on the internet. Acronyms like this are usually written in all capital letters but are not necessarily needed to be considered a standard acronym. Standard acronyms can be further divided into two:

i. Initialisms are acronyms consisting of initial letters which are read or pronounced separately. The researcher has observed that acronyms that fall under this category are pronounced per letter of the word. To form this netspeak, the initial letters of every word in a phrase, sentence or names are taken to create the acronym and the letters are then pronounced separately when referring to it. The researcher has also observed that some participants used an acronym when referring to the name of a public figure, like MP for Manny Pacquiao and CG for Catriona Gray.

ii. Pronounced as a new word is an acronym where the combination of letters can be read or pronounced as a whole word rather than separately.

b. Single-word Acronyms are single words which are further shortened by using only a few letters, usually two, to form an acronym. This differs from an abbreviation in a way that the first letters per syllable in the word are taken to form an acronym and not necessarily to delete a part in the word.

c. Phrasal or Sentence Acronyms are acronyms formed from a phrase or even a whole sentence by taking the first letters in each word. This category, like the Standard Acronyms, can further be divided into two:

i. Initialisms are acronyms consisting of initial letters which are read or pronounced separately. These initial letters are taken from each word in a phrase or sentence and are formed together to create an acronym. 
ii. Pronounced as a new word in phrasal or sentence acronyms are also formed by taking the initial letters of each word in a phrase or sentence and are combined to form the acronym, however, these letters are not pronounced separately but together like a new word itself.

\section{Onomatopoeia}

A total of 10 onomatopoeic words were found in this study.

Figure 4. List of Onomatopoeias Found in the Study

\begin{tabular}{|r|l|c|l|}
\hline No. & Item & Lexical Pattern (Netspeak) & Type \\
\hline 1 & acheche & Onomatopoeia & Transcription of laughter \\
\hline 2 & hahaha & Onomatopoeia & Transcription of laughter \\
\hline 3 & hehehe & Onomatopoeia & Transcription of laughter \\
\hline 4 & hihi & Onomatopoeia & Transcription of laughter \\
\hline 5 & hohoho & Onomatopoeia & Transcription of laughter \\
\hline 6 & hsksks & Onomatopoeia & Internet onomatopoeia \\
\hline 7 & huhi & Onomatopoeia & Transcription of cry \\
\hline 8 & huhuhu & Onomatopoeia & Transcription of cry \\
\hline 9 & hih & Onomatopoeia & Transcription of laughter \\
\hline 10 & sksksk & Onomatopoeia & Internet onomatopoeia \\
\hline
\end{tabular}

The onomatopoeias found in the corpus were analyzed and organized into three types as follows:

a. Transciptions of laughter are onomatopoeic words related to happiness which includes laughing, chuckle, giggle, etc.

b. Transcriptions of cry are onomatopoeic words limited only to crying.

c. Internet onomatopoeia refers to the onomatopoeia that is created, popularized and used within the Internet only.

\section{E. Internet Slang}

There was a total of 68 slang words found in the study, 50 of which were English and 18 were Filipino.

Figure 5. Partial List of Internet Slangs Found in the Study

\begin{tabular}{|c|c|c|c|c|}
\hline No. & Slang & Meaning & Lexical Pattern (Netspeak) & Type \\
\hline 1 & amats* & inebriate, tipsy or drunk & Internet Slang & Filipino Slang: Reverse Speech \\
\hline 2 & arat* $^{*}$ & let's go & Internet Slang & Filipino Slang: Reverse Speech \\
\hline 3 & awit* & $\begin{array}{l}\text { aw, sakit (aw, it hurts); used when in } \\
\text { an unfortunate situation }\end{array}$ & Internet Slang & $\begin{array}{l}\text { Filipino Slang: Meaning } \\
\text { Deviation }\end{array}$ \\
\hline 4 & basher & $\begin{array}{l}\text { a person who criticizes someone or } \\
\text { something; hater }\end{array}$ & Internet Slang & $\begin{array}{l}\text { English Slang: Meaning } \\
\text { Deviation }\end{array}$ \\
\hline 5 & bet & $\begin{array}{l}\text { term for affirmation or agreement; can } \\
\text { also suggest doubt or disbelief }\end{array}$ & Internet Slang & $\begin{array}{l}\text { English Slang: Meaning } \\
\text { Deviation }\end{array}$ \\
\hline 6 & boi & $\begin{array}{l}\text { another spelling for boy; reply for } \\
\text { when someone says/does something } \\
\text { stupid }\end{array}$ & Internet Slang & English Slang: Spelling \\
\hline 7 & bomb & $\begin{array}{l}\text { something or someone is very good; } \\
\text { someone who is very attractive }\end{array}$ & Internet Slang & $\begin{array}{l}\text { English Slang: Meaning } \\
\text { Deviation }\end{array}$ \\
\hline 8 & boom & $\begin{array}{l}\text { exclamation to draw attention to an } \\
\text { excellent outcome }\end{array}$ & Internet Slang & $\begin{array}{l}\text { English Slang: Meaning } \\
\text { Deviation }\end{array}$ \\
\hline 9 & cancer & stupid or ignorant & Internet Slang & $\begin{array}{l}\text { English Slang: Meaning } \\
\text { Deviation }\end{array}$ \\
\hline 10 & char* & $\begin{array}{l}\text { gaylingo for just kidding; shortened } \\
\text { version of charot }\end{array}$ & Internet Slang & Filipino Slang: Gaylingo \\
\hline 11 & charot $^{*}$ & gaylingo for just kidding & Internet Slang & Filipino Slang: Gaylingo \\
\hline 12 & choz $/$ chos $^{*}$ & $\begin{array}{l}\text { lie; adapted from echosera (liar in } \\
\text { gaylingo) }\end{array}$ & Internet Slang & Filipino Slang: Gaylingo \\
\hline 13 & clapback & $\begin{array}{l}\text { quick and effective response to } \\
\text { criticism }\end{array}$ & Internet Slang & English Slang: Social Media \\
\hline 14 & cyst & spelling variation of sis & Internet Slang & English Slang: Spelling \\
\hline 15 & doggo & a dog; full-sized pupper & Internet Slang & English Slang: Spelling \\
\hline
\end{tabular}

Internet slang is divided by the researcher into two types for better analysis and interpretation: English slang and Filipino Slang. These were further analyzed and categorized in the next page:

a. English Slangs are slang words in the English language. These words are very popular on the Internet, and some words may be used only in the context of the Internet. English slangs that are found in the study have the following characteristics:

i. Meaning deviation wherein the standard definition of the word has been changed to a new one that fits Internet uses more. However, the researcher has observed that some of the words that deviated from their original meaning may not be taken well by people when used outside the Internet. For example, the phrase "killing it" is used when someone does something really well (Urban Dictionary, 2020); however, when used outside the Internet, it may cause some understanding. 
ii. Spelling of some of the Internet slangs has added letters to the original word. From the observation of the researcher, the added letter adds emphasis and stress to the word they want to say.

iii. Social media slang are slangs that are created on the Internet. These words have been created with the influence of various communities on the Internet (like gaming, social networking sites, etc.) and are not in the dictionary, therefore, it is the users that give them meaning and life.

b. Filipino Slang is slang words that are popular and are used in the Philippines. Unlike English slang which focuses on meaning deviation and change, Filipino slang as observed by the researcher focuses on the creation of slang words as well as word structures. However, one common category both in English and Filipino is social media slang. Additionally, Filipino slang has the following characteristics:

i. Reverse speech is a kind of slang in Filipino where the words are spelt backwards or pronounced invertedly.

ii. Gay lingo is the use of terms and words from the gay community.

iii. Pronunciation is the nonstandard pronunciation and spelling of English phrases, often applying the Filipino sounds to English words/phrases.

iv. Bilingual phrases are Filipino slang that uses a combination of English and Filipino words.

v. Meaning deviation is also present in Filipino slang, wherein the definition of an English word is different when used in the Philippines. This characteristic is also seen in a few Filipino words that change in meaning when used as a slang.

vi. Social media slang is a slang created on the Internet. These words have been created with the influence of various communities on the Internet (like gaming, social networking sites, etc.) and are not in the dictionary. Therefore it is the users that give them meaning and life.

\section{F. Coinage}

There was a total of 17 coinages found in the study.

Figure 6. List of Coinages Found in the Study

\begin{tabular}{|r|l|l|l|l|}
\hline No. & Item & Meaning & Lexical Pattern (Netspeak) & Type \\
\hline 1 & badge & awarded to most active users in a Page & Coinage & Social Media \\
\hline 2 & blog & $\begin{array}{l}\text { a regularly updated website by an individual, } \\
\text { often written in an informal or conversational } \\
\text { style }\end{array}$ & Coinage & Social Media \\
\hline 3 & download & $\begin{array}{l}\text { copy data from a computer system to another } \\
\text { via the Internet }\end{array}$ & Coinage & Internet Process \\
\hline 4 & fake news & $\begin{array}{l}\text { information presented as news, often false, } \\
\text { malicious and misleading }\end{array}$ & Coinage & Phenomena \\
\hline 5 & fake newsmaker & people who create and spread fake news & Coinage & Phenomena \\
\hline 6 & GIF & $\begin{array}{l}\text { Graphics Interchange Format; it is a moving } \\
\text { picture }\end{array}$ & Coinage & Internet Process \\
\hline 7 & hashtag & $\begin{array}{l}\text { the pound sign (\#) used to identify content on } \\
\text { a specific topic online }\end{array}$ & Coinage & Social Media \\
\hline & & $\begin{array}{l}\text { a public figure who has established authority } \\
\text { in a specific industry, has a huge audience } \\
\text { and can persuade others based on their } \\
\text { personal recommendations }\end{array}$ & & Coinage \\
\hline 8 & influencer & $\begin{array}{l}\text { act of making a program ready for execution } \\
\text { or use on a computer }\end{array}$ & Coinage & Internet Process \\
\hline 9 & install & $\begin{array}{l}\text { a phrase to dismiss people associated with } \\
\text { the Baby Boomer generation and generally } \\
\text { older people }\end{array}$ & Coinage & Phenomena \\
\hline 10 & ok boomer & $\begin{array}{l}\text { spoil a photograph by unexpectedly appearing } \\
\text { in the frame when a picture is taken }\end{array}$ & Coinage & Phenomena \\
\hline 11 & photobomb & resharing of a tweet in your own profile & Coinage & Social Media \\
\hline 12 & retweet & $\begin{array}{l}\text { a photograph of oneself taken personally and } \\
\text { shared in social media }\end{array}$ & Coinage & Phenomena \\
\hline 13 & selfie & $\begin{array}{l}\text { another word for fan; obsessive fan of a } \\
\text { public figure or celebrity }\end{array}$ & Coinage & Phenomena \\
\hline 14 & stan & $\begin{array}{l}\text { currently popular and discussed online in } \\
\text { social networking sites }\end{array}$ & Coinage & Phenomena \\
\hline 15 & trending & post made in Twitter & Social Media \\
\hline 16 & tweet & transfer data from one computer to another & Internet & \\
\hline 17 & upload & & Coinage & \\
\hline
\end{tabular}

The coinages found in the corpus were analyzed and organized into three types:

a. Internet processes are coinage on Internet that are influenced by the processes that are exclusive to Internet use like download, upload and install.

b. Social Media coinage is words influenced by the specific functions of a social media platform like Twitter, where the word tweet became a root word for terms like retweet or quote retweet. Words that were created based on networking sites are also under this category, like a blog.

c. Phenomena coinage are words influenced by the happenings on the Internet as well as the users and their behavior in social media. Words are coined in order to have a word that would describe them.

\section{G. Blending}

The blended words that were found in the study were only 6 . The blended words found in the corpus have the same characteristic, which is simply combining two words to form one word.

Figure 7. List of Blended Words Found in the Study 


\begin{tabular}{|r|l|l|c|l|}
\hline No. & Item & Expansion & Lexical Pattern (Netspeak) & Type \\
\hline 1 & cosplay & costume + play & Blending & Two-word combination \\
\hline 2 & fitspiration & fitness + inspiration & Blending & Two-word combination \\
\hline 3 & gandara/gandarra & ganda (beautiful) + Sandara & Blending & Two-word combination \\
\hline 4 & netizen & Internet + citizen & Blending & Two-word combination \\
\hline 5 & Makatizen & Makati + citizen & Blending & Two-word combination \\
\hline 6 & vlog & video + blog & Blending & Two-word combination \\
\hline
\end{tabular}

In the blending found in the corpus, items 1-3 are blending of words that share both the properties of the two words. In item 1, costume and play both combine to create cosplay which is defined as the practice of "dressing up as a character from a movie, book or video game". Item 2's fitspiration is "a person or thing that serves as motivation for someone to sustain or improve health and fitness". Item 3's gandara/gandarra is actually a gay lingo that combines ganda and Sandara Park and this blended word simply means pretty or beautiful. Meanwhile, items 4-6 are blends where the first element modifies the second one. The blended word in item 4, netizen, is a combination of Internet and citizen and refers to a member of the community of Internet users. Item 5 has adapted the meaning of item 4 and applied it to their local city, Makati + citizen combined together form the word Makatizen, which simply means a citizen of Makati City. Lastly, item 6's blended word vlog is a combination of video and blog. Vlog is simply a form of blog in a different medium, evident in the word itself, which is video.

\subsection{Implications to Language Studies in the Philippines}

Through the analysis of the data, the researcher observed that the language used in online communication is changing and deviating from that of the standard usage. This study analyzed and observed seven Netspeak features in the social media accounts of Filipinos, as well as their extent of usage in the most popular websites and domains of pop culture.

Netspeak in the Philippines provides an interesting and vast array of language use that language studies can take advantage of. From the findings of the study, the following implications that may have a bearing on language studies in the Philippines were drawn:

1. From the ever-evolving language of the Internet, with all of the inputs from its users, several linguistic properties have emerged from this growth. Evidently, social media platforms and domains of pop culture have brought about much of the emergence of these linguistic properties which comprise what we now call as Netspeak. Central to Netspeak are its lexical features which were the focus of this study. It is important, therefore, for language educators to be always adept at these features and see how they could be utilized towards meaningful and relevant teaching.

2. Knowledge of Netspeak can also help language educators to identify its effects on the use of standard English, which is the prescribed language of communication in formal writing, and suggest some measures to avoid possible problems that may arise from this. For example, teaching students to write their own resumé for future job opportunities using standard English while in creative writing classes, they can make use of netspeak in their essays. It is important to help students be able to distinguish which is the standard form of writing and what is considered creative. In order for them to be able to differentiate which is which, they need to be exposed to the language for them to experience and see first hand what to avoid in formal writing.

3. The present study can be used as a reference to teach language evolution and language variation. That even if Netspeak is considered nonstandard and unconventional, it can make students realize that creative language is still communicable, that being creative helps in keeping the language active and even help in improving it. Netspeak may even be used in lessons in phonology, morphology and even semantics. The language used in the Internet can be broken down and analyzed to the smallest unit of speech.

4. The present study may inspire language scholars to conduct more research on similar or other language phenomena to enrich the field of sociolinguistics and Internet linguistics.

\section{Conclusion}

This paper shed light on the characteristics of netspeak found in Filipino social media and pop culture domains. The data collected and analyzed disclosed that abbreviations and homophones were the emerging lexical patterns of Netspeak in the social media accounts of the Filipinos and that the extent of Netspeak usage in the social media platforms shows a high frequency of certain Netspeak features in each platform. In Facebook, abbreviations and homophones were the most prevalent features. In Instagram, abbreviations and onomatopeias were used more than any other features. In Twitter, acronyms and onomatopeias were of the highest frequency of usage. Among all three platforms, Twitter had the highest total frequencies of Netspeak features while Facebook had the lowest. Some of the features found were influenced by the social media platforms, including the restrictive character limit of Twitter and the photo-centric nature of Instagram. The extent of Netspeak usage in the domains of pop culture was also evident in a high frequency of certain Netspeak features. In entertainment, onomatopoeias and homophones were frequently used; in fashion, abbreviations and homophones, and in politics, acronyms and abbreviations were often used. Lastly, in sports, abbreviations and homophones were also frequently used. Among all domains of pop culture, the 
usage of Netspeak lexical features was most prevalent in the Politics domain and least in the Sports domain. There were Netspeak features found to be unique to a pop culture domain which includes high frequencies of laughter in the entertainment domain, high usage of the coined term fake news in the Politics domain, the occurrence of domain-exclusive slangs in the fashion domain, and the prevalence of abbreviated congratulatory messages in the Sports domain.

Netspeak is a dynamic language that is fast-changing and ever evolving. Social media platforms and pop culture domains shape the language of the internet, just as Netspeak shapes the contents of social media platforms and pop culture. Since Netspeak is the language of the current generation of students, language educators, especially in the Philippines, should be familiar with and updated on its features, which they could utilize in their teaching, to make classroom experience for their students more interesting and relevant. The findings of the study may serve as a reference to linguistic studies in the Philippines. The present study focused on English and Filipino Netspeak only, however, the Philippines is a country with a lot of languages and it is recommended that the study be extended to these languages. It may be interesting to see if there are netspeak that are unique to them and may even come up with new types of Netspeak.

Funding: This research received no external funding.

Acknowledgments: The author would like to extend their thanks to their adviser, Dr. Mildred B. Go for the support. Also, to the friends and family of the author for helping whenever it is needed.

Conflicts of Interest: The authors declare no conflict of interest.

\section{References}

[1] Besmano, J., Dimaranan, H., Fernandez, J., \& Valguna, R. (2017). Identifying political fake news in the Philippines. https://doi.org/10.13140/RG.2.2.31885.84964

[2] Clement, J. (2020). Most common languages used on the internet 2020. Retrieved from https://www.statista.com/statistics/262946/share-ofthe-most-common-languages-on-the-internet/

[3] Crystal, D. (2001). Language and the internet. Cambridge: Cambridge University Press.

[4] Crystal, D. (2005). Language and the internet. Cambridge: Cambridge University Press.

[5] Gustilo, L. \& Dino, C. (2017). Old speak or young speak: An analysis of netspeak features in Filipino netspeak. Advanced Science Letters, 23(2), 1099-1103. https://doi.org/10.1166/asl.2017.7507

[6] Liu, W. \& Liu, W. (2014). Analysis on the word-formation of English netspeak neologism. Journal of Arts and Humanities, 22-30.

[7] Nasir, K. \& Al-Ghizzy, M. (2019). Linguistic features of netspeak: abbreviations, acronyms and punctuation marks. University of Thi-Qar Journal of Education for Humanities Science, 1(1). Retrieved from: https://jedh.utq.edu.iq/index.php/main/article/view/1/1

[8] Nassaji, H. (2015). Qualitative and descriptive research: Data type versus data analysis. Language Teaching Research, 19(2), $129-132$.

[9] Ohiagu, O. \& Okarie, V. (2014). Social media shipping and transmitting popular culture. Covenant Journal of Communication (CJOC), 2(1), 93-108.

[10] Villares, R. (2017). A Corpus-based Analysis of Non-Standard English Features in the Microblogging Platform Tumblr [Conference Paper] (pp. 295-303). AESLA 2016, Alicante. https://www.researchgate.net/publication/281775762_A_Corpus-based_Analysis_of_NonStandard_English_Features_in_the_Microblogging_Platform_Tumblr_pp_295-303

[11] Wang, D. Z., \& Wang, S. S. (2017). Research on features of chatroom netspeak from a stylistic view. Studies in Literature and Language, 15(1), 43-36. https://doi.org/10.3968/9780.

[12] Yeo, D. \& Ting, S. (2017). Netspeak features in facebook communication of Malaysian university students. Journal of Advanced Research in Social and Behavioural Sciences, 6(1), 81-90. 